\title{
Characteristics of Granular Boehmite and Its Ability to Adsorb Phosphate from Aqueous Solution
}

\author{
Fumihiko Ogata, Hisato Tominaga, Moe Kangawa, Kenji Inoue, and Naohito Kawasaki* \\ Faculty of Pharmacy, Kinki University; 3-4-1 Kowakae, Higashi-Osaka, Osaka 577-8502, Japan. \\ Received February 29, 2012; accepted June 4, 2012
}

In this study, we investigated the surface properties of granulated boehmite with vinyl acetate (G-BE20) and measured the amount of phosphate it adsorbed and the effect of contact time and solution pH on the adsorption process. The specific surface area $\left(144.9 \mathrm{~m}^{2} / \mathrm{g}\right)$ and the number of surface hydroxyl groups $(0.88 \mathrm{mmol} / \mathrm{g})$ of G-BE20 were smaller than those of virgin boehmite (BE), which gave a specific surface area and number of surface hydroxyl groups of $297.0 \mathrm{~m}^{2} / \mathrm{g}$ and $1.08 \mathrm{mmol} / \mathrm{g}$, respectively. The amount of phosphate adsorbed increased with the temperature. The isotherm model of Langmuir was used to fit experimental adsorption equilibrium data for phosphate adsorption onto G-BE20. The calculated thermodynamic parameters show the spontaneous and endothermic nature of the adsorption process. The equilibrium adsorption onto G-BE20 was reached within $16 \mathrm{~h}$ and the amount of phosphate adsorbed was $8.4 \mathrm{mg} / \mathrm{g}$. The kinetic mechanism of phosphate uptake was evaluated with two different models: the Largergren pseudo first- and pseudo second-order models. The data obtained showed a better fit to the pseudo second-order model (0.991) than to the pseudo first-order model $(0.967)$, as indicated by the $r$ values. The rate constants for the adsorption of phosphate onto G-BE20 were calculated as $0.4811 / \mathrm{h}$ and $0.029 \mathrm{~g} / \mathrm{mgh}$. The adsorption of phosphate onto G-BE20 was the maximum in the $\mathrm{pH}$ range $3.0-4.0$.

Key words phosphate; adsorption; boehmite

Phosphorus is an important nutrient involved in several biochemical reactions, and it cannot be substituted by other elements. It is widely used in agriculture and industry. ${ }^{1)}$ The presence of trace amounts of phosphorus, exceeding about $1 \mathrm{mg} / \mathrm{L}$, in treated wastewater can stimulate algal growth (eutrophication); phosphorus is usually considered a rate-limiting factor for algal growth. ${ }^{2)}$ Algal blooms lead to short- and longterm environmental and aesthetic problems in lakes, coastal areas, and other confined water bodies. ${ }^{3)}$ Moreover, phosphate is an exhaustible resource, and Japan depends solely on imports owing to a lack of native rock phosphate. As a consequence, phosphate removal and recovery from wastewater has been considered an important factor related to environmental sustainability. ${ }^{4)}$

Several physicochemical and biological processes have been investigated for the removal of dissolved nutrients in water and wastewaters. ${ }^{5-9)}$ They include adsorption methods, physical processes (settling and filtration), chemical precipitation (with aluminum, iron, and calcium salts), and biological processes that rely on biomass growth (bacteria, algae, and plants) or intracellular bacterial polyphosphate accumulation. $^{10)}$ Adsorption is one of the most attractive approaches in water treatment, and it has the advantage of having high removal efficiency without producing harmful by-products. ${ }^{11)}$ It is also well known that phosphates have a strong affinity for mineral surfaces. ${ }^{12)}$ Its affinity for hydroxide surfaces depends not only on the anion's complexing capacity, which allows phosphates to bind to surface groups through ligand exchange reactions, but also on electrostatic interactions with the charged hydroxide surfaces. ${ }^{13)}$

Boehmite (BE), a form of aluminum oxyhydroxide, is a very inexpensive adsorbent and can be recycled using a desorption solution. It also possesses anion exchange ability due to the surface hydroxyl groups. ${ }^{14)} \mathrm{BE}$, the molecular

The authors declare no conflict of interest. formula of $(\mathrm{AlOOH})_{n}$, is colorless, insoluble in water, and exhibits acid, base, and thermal resistance, which makes it useful as a catalyst, an abrasive, or a filler. However, powdered $\mathrm{BE}$ needs to be granulated with a binder for use in fields; it is not useful for removal of phosphate because plugging occurs, which indicates that the particle size of the BE adsorbent is too small. Moreover, the amount of phosphate adsorbed onto BE can be easily desorbed and recovered using sodium hydroxyl solution. ${ }^{15)}$ This technology can also be used in the field. Although the phosphate adsorption ability of $\mathrm{BE}$ is widely known, ${ }^{14)}$ the phosphate adsorption ability of granular $\mathrm{BE}$ has never been reported.

In this study, we produced granular BE with vinyl acetate as an organic binder. The phosphate adsorption ability, effect of contact time and $\mathrm{pH}$, and the adsorption mechanism of phosphate were investigated for examining the use of the $\mathrm{BE}$ in the field.

\section{Experimental}

Materials For the preparation of boehmite (AD220NS: Tomita Pharmaceutical Co., Ltd., Japan), noncrystalline aluminum hydroxide was placed in an aqueous medium. After heat treatment at $90-100^{\circ} \mathrm{C}$ for $1-3 \mathrm{~h}$, the aluminum oxyhydroxide obtained was spray-dried. The main chemical composition of the resultant aluminum oxyhydroxide was $\mathrm{AlOOH}$, less than $0.1 \% \mathrm{Cl}^{-}$, and less than $0.8 \% \mathrm{SO}_{4}^{2-}$. Its loss of mass upon drying and its $\mathrm{pH}$, mean particle size, and pore volume were $7.8 \%, 8.2,100 \mu \mathrm{m}$, and $0.402 \mathrm{~mL} / \mathrm{g}$, respectively.

Granular BE was prepared by mixing vinyl acetate with virgin $\mathrm{BE}$ and allowing the mixture to dry. Hereafter, we refer to virgin $\mathrm{BE}$ containing about $20 \%$ vinyl acetate as G-BE20 (Columnar construction: diameter $3 \mathrm{~mm} \times$ height $5 \mathrm{~mm}$ ).

Thermogravimetric-differential thermal analysis (TG-DTA) and scanning electron microscopy (SEM) were carried out using a DTG-60AH (Shimadzu, Japan) and a JSM-5500LV (JEOL, Japan), respectively. The specific surface area of each 


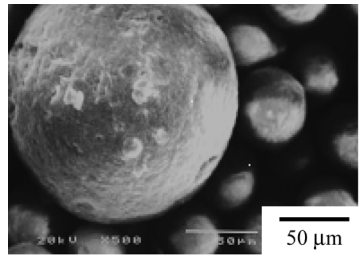

Virgin BE $(\times 200)$

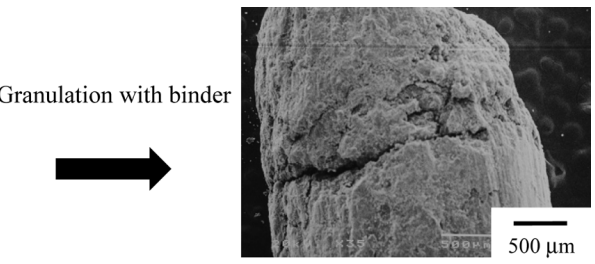

G-BE20 $(\times 500)$

Fig. 1. SEM Images of Virgin BE and G-BE20

sample was measured using a Flowsorb II 2300 (Micromeritics, Japan), the number of surface hydroxyl groups was measured by fluoride ion adsorption, ${ }^{16)}$ and the $\mathrm{pH}$ of each solution was measured using a digital $\mathrm{pH}$ meter (Mettler-Toledo International Inc., Japan).

Phosphate solution (using distilled water) or environmental water (using water from Lake Biwa) was prepared by $\mathrm{NaH}_{2} \mathrm{PO}_{4} \cdot 2 \mathrm{H}_{2} \mathrm{O}$ (Wako Pure Chemical Industries, Ltd., Osaka, Japan).

Adsorption Isotherms G-BE20 (0.05 g) was added to $50 \mathrm{~mL}$ of phosphate solution or environmental water at different concentrations $(1-50 \mathrm{mg} / \mathrm{L})$ of $\mathrm{pH} 5.32-6.00$ (ionic strength: $\left.0.1 \times 10^{-4}-5.2 \times 10^{-4}\right)$. The suspension was shaken at 15,25 , and $35^{\circ} \mathrm{C}$ for $24 \mathrm{~h}$ at $100 \mathrm{rpm}$ and then filtrated using a $0.45-\mu \mathrm{m}$ membrane filter. The concentration of phosphate was measured using DR/890 (HACH, U.S.A.). The amount of phosphate adsorbed onto the adsorbent was calculated as follows by using the concentration before and after adsorption:

$$
X=\left(C_{0}-C_{\mathrm{e}}\right) V / M
$$

where $X$ is the amount of phosphate adsorbed $(\mathrm{mg} / \mathrm{g}), C_{0}$ is the concentration before adsorption $(\mathrm{mg} / \mathrm{L}), C_{\mathrm{e}}$ is the concentration after adsorption $(\mathrm{mg} / \mathrm{L}), V$ is the solvent volume $(\mathrm{L})$, and $M$ is the mass of the adsorbent $(\mathrm{g})$.

Effect of Contact Time and Solution pH on the Adsorption of Phosphate onto G-BE20 The $\mathrm{pH}$ of the solution was adjusted from 2 to 7 by adding suitable volumes of $0.1 \mathrm{~mol} / \mathrm{L}$ hydrochloric acid or $0.1 \mathrm{~mol} / \mathrm{L}$ sodium hydroxide solution. G-BE20 $(0.05 \mathrm{~g})$ was added to $50 \mathrm{~mL}$ of phosphate solution at $50 \mathrm{mg} / \mathrm{L}$. The suspension was shaken at $25^{\circ} \mathrm{C}$ for $24 \mathrm{~h}$ at $100 \mathrm{rpm}$ and then was filtrated using a $0.45-\mu \mathrm{m}$ membrane filter.

Similarly, G-BE20 (0.05 g) was added to $50 \mathrm{~mL}$ of phosphate solution at $50 \mathrm{mg} / \mathrm{L}$, and after $1-24 \mathrm{~h}$, the solution was filtrated using a $0.45-\mu \mathrm{m}$ membrane filter. The amount of phosphate adsorbed onto G-BE20 was calculated using Eq. 1.

\section{Results and Discussion}

Characteristics of G-BE20 SEM images of virgin BE and G-BE20 show that virgin BE can be granulated with vinyl acetate (Fig. 1) and that the particle size of G-BE20 is larger than that of virgin BE. The results of TG-DTA of G-BE20 show that the adhesive water evident in G-BE20 was dehydrated at about $105^{\circ} \mathrm{C}$ and that the peak for the combustion of the binder (vinyl acetate) occurred at around $462^{\circ} \mathrm{C}$ (Fig. 2).

The specific surface area $\left(144.9 \mathrm{~m}^{2} / \mathrm{g}\right)$ and the number of surface hydroxyl groups $(0.88 \mathrm{mmol} / \mathrm{g})$ of G-BE20 were less than those of virgin $\mathrm{BE}$, and these values gave the specific surface area and number of surface hydroxyl groups as $297.0 \mathrm{~m}^{2} / \mathrm{g}$ and $1.08 \mathrm{mmol} / \mathrm{g}$, respectively. ${ }^{14)}$ These results

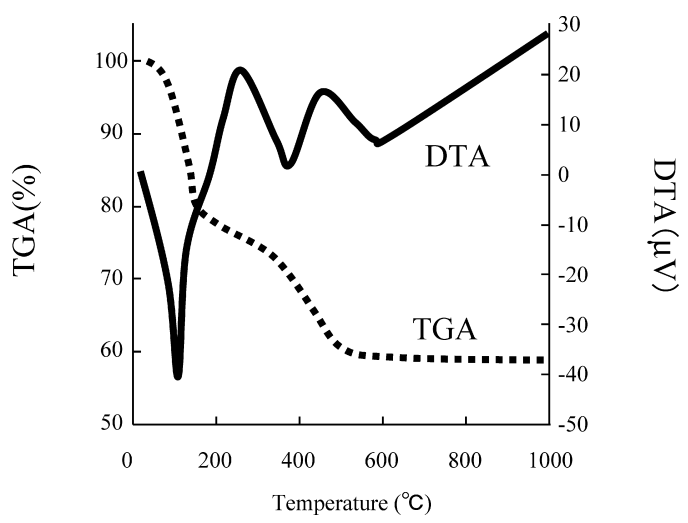

Fig. 2. TG-DTA of G-BE20

indicate that the particle size of G-BE20 increased upon granulation with the binder. However, the binder masked available adsorption sites on the G-BE20 surface. The $\mathrm{pH}$ of the G-BE20 solution was 6.37.

Isotherm for Adsorption of Phosphate onto G-BE20 The isotherm for the adsorption of phosphate onto G-BE20 is shown in Fig. 3, and it indicates that the amount of phosphate adsorbed increased with the temperature. The equilibrium adsorption capacities of phosphate at 15,25 , and $35^{\circ} \mathrm{C}$ were $6.2,8.7$, and $10.3 \mathrm{mg} / \mathrm{g}$, respectively. We previously reported that the amount of phosphate adsorbed onto virgin or calcined $\mathrm{BE}$ depends on the specific surface area and the number of hydroxyl groups in the BE. The amount of phosphate adsorbed onto calcined BE increased with the temperature. With G-BE20, a similar tendency was seen in the calcined BE. Further, the solution $\mathrm{pH}$ increased from $5.32-6.00$ to $5.89-6.72$ which indicated that the surface hydroxyl groups of BE was exchanged with phosphate.

The isotherm model of Langmuir was used to fit the experimental adsorption equilibrium data for phosphate adsorption onto G-BE20. ${ }^{17)}$ These models are represented mathematically as follows:

$$
X=a W_{S} C_{\mathrm{e}} /\left(1+a W_{S}\right)
$$

where $X(\mathrm{mg} / \mathrm{g})$ is the amount of phosphate adsorbed, $a(\mathrm{~L} / \mathrm{mg})$ is a constant related to the affinity to the binding sites and to the adsorption, $W_{S}(\mathrm{mg} / \mathrm{g})$ is the maximum monolayer adsorption capacity, and $C_{\mathrm{e}}(\mathrm{mg} / \mathrm{L})$ is the equilibrium concentration.

Langmuir constants for the adsorption of phosphate onto G-BE20 are listed in Table 1. From the table, the Langmuir constant $a$ at 15,25 , and $35^{\circ} \mathrm{C}$ is seen to be $0.05,0.44$, and 1.32, respectively. These results indicated an endothermic process. Moreover, this reaction is the spontaneous nature of the adsorption process and the feasibility of the adsorption 


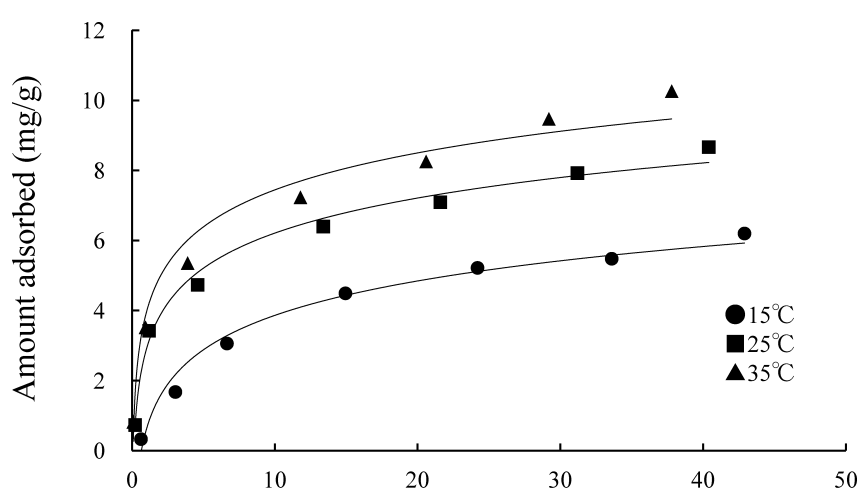

Equilibrium concentration $(\mathrm{mg} / \mathrm{L})$

Fig. 3. Adsorption Isotherms of Phosphate onto G-BE20 at Different Temperatures

of phosphate onto G-BE20. The adsorption of phosphate onto G-BE20 may involve not only chemical adsorption but also physical adsorption. The correlation coefficient at 15, 25, and $35^{\circ} \mathrm{C}$ is $0.998,0.996$, and 0.994 , respectively.

Effect of Contact Time and Solution pH on the Adsorption of Phosphate onto G-BE20 The rate of phosphate adsorption onto G-BE20 is shown in Fig. 4. It can be seen that the equilibrium adsorption onto G-BE20 was reached within about $16 \mathrm{~h}$ and the amount of phosphate adsorbed was $8.4 \mathrm{mg} / \mathrm{g}$. Faster reactions have previously been reported for the adsorption of phosphate on iron oxide tailings, ${ }^{17)}$ bauxite, ${ }^{18)}$ and alunite. $\left.{ }^{19}\right)$ These reports indicated that the adsorption reached equilibrium in $25-60 \mathrm{~min}$. The reaction between phosphate and the adsorbent is of primary importance in the use of adsorbents in wastewater treatment.

The kinetic mechanism of phosphate uptake was evaluated with two different models: the Largergren pseudo first- and pseudo second-order models. ${ }^{20)}$ The pseudo first-order equation takes the form

$$
\ln \left(q_{\mathrm{e}}-q_{\mathrm{t}}\right)=\ln q_{\mathrm{e}}-k_{1} t
$$

where $q_{\mathrm{t}}$ is the amount of phosphate adsorbed at time $t(\mathrm{mg} / \mathrm{g})$, $q_{\mathrm{e}}$ is the amount of phosphate bound at equilibrium $(\mathrm{mg} / \mathrm{g})$, and $k_{1}$ is the equilibrium rate constant for pseudo first-order kinetics.

The pseudo second-order equation is expressed as

$$
t / q_{\mathrm{t}}=1 / k_{2} q_{\mathrm{e}}^{2}+t / q_{\mathrm{e}}
$$

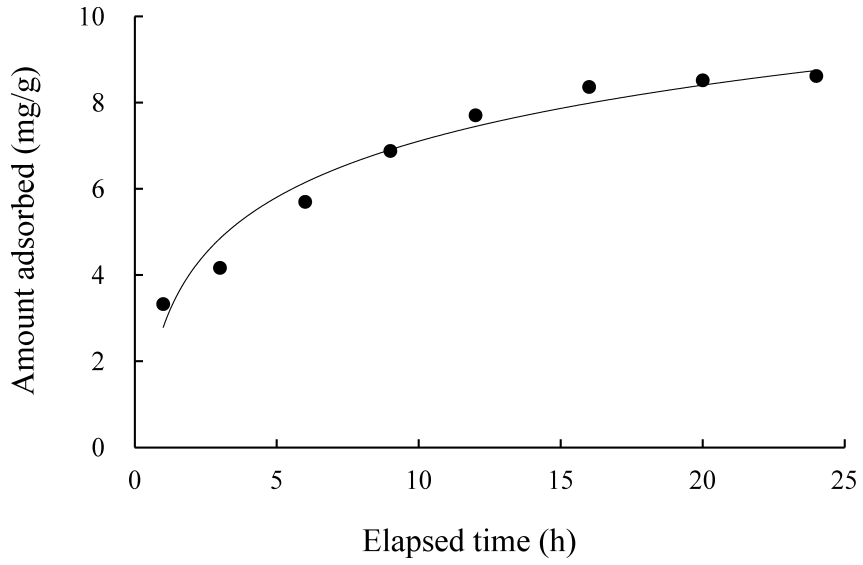

Fig. 4. Adsorption Rate of Phosphate onto G-BE20

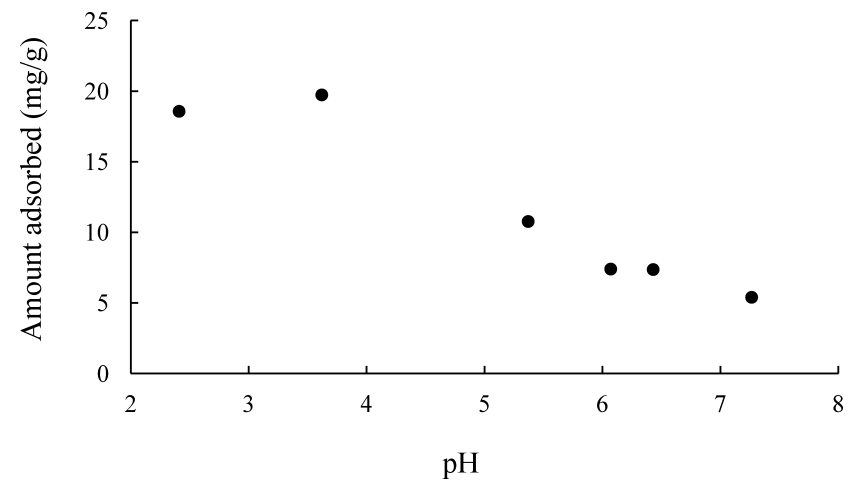

Fig. 5. Amount of Phosphate Adsorbed onto G-BE20 at Different $\mathrm{pH}$

where $k_{2}$ is the equilibrium rate constant for the pseudo second-order kinetics ( $/ \mathrm{mg}$ h). The data obtained showed a better fit to the pseudo second-order model (0.991) than to the pseudo first-order model (0.967), as indicated by the $r$ values in Table 2. The rate constants for the adsorption of phosphate on G-BE20 were calculated as $0.4811 / \mathrm{h}$ and $0.029 \mathrm{~g} / \mathrm{mg} \mathrm{h}$.

The $\mathrm{pH}$ of the aqueous solutions containing the adsorbent is an important parameter in the adsorption process. The adsorption of phosphate onto G-BE20 as a function of $\mathrm{pH}$ is shown in Fig. 5. It can be seen that the adsorption has strong $\mathrm{pH}$ dependence. In the $\mathrm{pH}$ range 3.0-4.0, the adsorption reached the maximum. Generally, phosphate exists in three forms in diluted aqueous solutions. In a strongly basic solution,

Table 1. Langmuir Constants for Phosphate Adsorption onto G-BE20

\begin{tabular}{ccccc}
\hline \hline \multirow{2}{*}{ Sample } & Temperature $\left({ }^{\circ} \mathrm{C}\right)$ & \multicolumn{3}{c}{ Langmuir constants } \\
\cline { 3 - 5 } & & Ws $(\mathrm{mg} / \mathrm{g})$ & $a(\mathrm{~L} / \mathrm{mg})$ & $r$ \\
\hline \multirow{2}{*}{ G-BE20 } & 15 & 11.47 & 0.05 & 0.998 \\
& 25 & 8.38 & 0.44 & 0.996 \\
& 35 & 7.69 & 1.32 & 0.994 \\
\hline
\end{tabular}

Table 2. Pseudo First- and Second-Order Constants for Phosphate Adsorption onto G-BE20

\begin{tabular}{ccccc}
\hline \hline Sample & \multicolumn{1}{c}{ Model } & $q_{\mathrm{e}}(\mathrm{mg} / \mathrm{g})$ & $k_{1}\left(\mathrm{~h}^{-1}\right)$ or $k_{2}(\mathrm{~g} / \mathrm{mgh})$ & $r$ \\
\hline \multirow{2}{*}{ G-BE20 } & Pseudo first-order & 6.1 & 0.481 & 0.967 \\
& Pseudo second-order & 9.9 & 0.029 & 0.991 \\
\hline
\end{tabular}




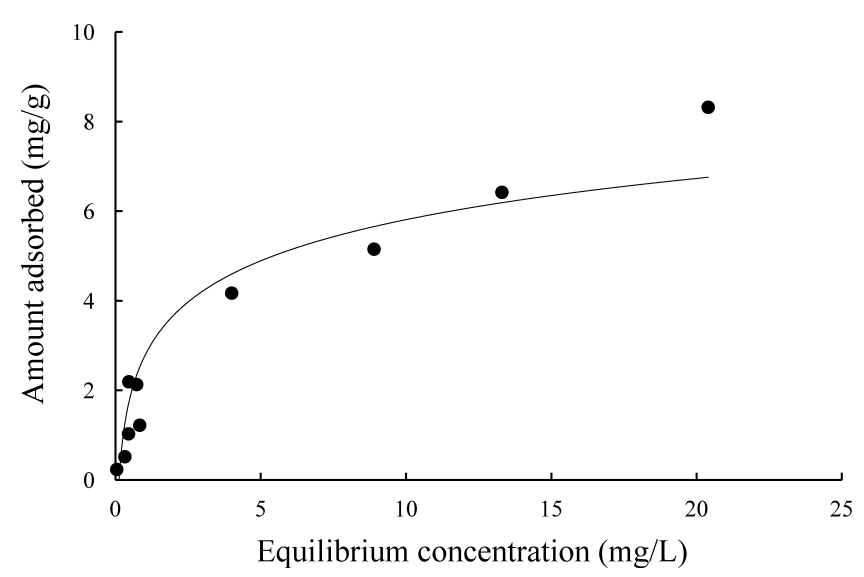

Fig. 6. Adsorption Isotherm of Phosphate onto G-BE20 in Environmental Water

$\mathrm{PO}_{4}{ }^{3-}$ predominates. In weakly basic conditions, $\mathrm{HPO}_{4}{ }^{2-}$ predominates; in weakly acidic conditions, $\mathrm{H}_{2} \mathrm{PO}_{4}^{-}$predominates; and in strongly acidic conditions, $\mathrm{H}_{3} \mathrm{PO}_{4}$ predominates. Here, in our case, since the adsorption was found to be the maximum at $\mathrm{pH} 3.5$, it can be said that $\mathrm{H}_{2} \mathrm{PO}_{4}^{-}$is predominant. We have previously reported that the phosphate ion $\left(\mathrm{H}_{2} \mathrm{PO}_{4}^{-}\right)$ was exchanged with surface hydroxyl groups on powder BE. Moreover, Sverjensky and Watanabe et al. were reported that the surface charge characteristics of aluminum hydroxide must related to the $\mathrm{pH}$ dependency of phosphate adsorption on the aluminum hydroxide. ${ }^{21,22)}$

Amount of Phosphate Adsorbed onto G-BE20 in Environmental Water The adsorption isotherm of phosphate adsorption onto G-BE20 in environmental water is shown in Fig. 6. The adsorption amount in environmental water agreed with that in aqueous solutions. This result implied that the components of environmental water did not affect the adsorption. Sometimes the components of environmental water competed with phosphate for adsorption in aqueous solutions. Therefore, G-BE20 was found to be useful for the adsorption of phosphate in environmental water.

\section{Conclusion}

Results from this study indicated that G-BE20 has a high phosphate removal capacity. BE was granulated with vinyl acetate and the properties of the resulting G-GB20 were evaluated. The specific surface area and the number of surface hydroxyl groups of G-BE20 were smaller than those of virgin $\mathrm{BE}$, and the amount of phosphate adsorbed increased with the temperature. The data obtained showed a better fit to the pseudo second-order model (0.991) than to the pseudo first-order model $(0.967)$, as indicated by the $r$ values. The rate constants for the adsorption of phosphate onto G-BE20 were calculated to be $0.481 \mathrm{l} / \mathrm{h}$ and $0.029 \mathrm{~g} / \mathrm{mgh}$. Moreover, the amount of phosphate adsorbed onto G-BE20 in environmental water agreed with that absorbed onto G-BE20 in aqueous solutions. The results also showed that the components of environmental water did not affect the absorption of phosphate onto G-BE20. These results indicate that G-BE20 will be useful for the removal of phosphate in environmental water.

Acknowledgments This work was financially supported by "Antiaging Center Project" for Private Universities from Ministry of Education, Culture, Sports, Science and Technology of Japan (2008-2012).

\section{References}

1) Liu Y., Villalba G., Ayres R. U., Schrode H., J. Ind. Ecol., 12, 229-247 (2008).

2) Peleka E. N., Deliyanni E. A., Desalination, 245, 357-371 (2009).

3) Oguz E., Gurses A., Yalcin M., Water Air Soil Pollut., 148, 279-287 (2003).

4) Zhang T., Ding L., Ren H., Guo Z., Tan J., J. Hazard. Mater., 176, 444-450 (2010).

5) Jutidamrongphan W., Park K. Y., Dockko S., Choi J. W., Lee S. H., Environ. Chem. Lett., 10, 21-28 (2012).

6) Yue Q., Zhao Y., Li Q., Li W., Gao B., Han S., Qi Y., Yu H., J. Hazard. Mater., 176, 741-748 (2010).

7) Anirudhan T. S., Rauf T. A., Rejeena S. R., Desalination, 285, 277-284 (2012).

8) Zach-Maor A., Semiat R., Shemer H., J. Colloid Interface Sci., 363, 608-614 (2011).

9) Kamiyango M. W., Sajidu S. M. I., Masamba W. R. L., Afr. J. Biotechnol., 10, 11972-11982 (2011).

10) Rodrigues L. A., daSilva M. L. C. P., Desalination, 263, 29-35 (2010).

11) Zhang S., Li X. Y., Chen J. P., J. Colloid Interface Sci., 343, 232 238 (2010).

12) Torrent J., Schwertmann U., Barron V., Clay Miner., 40, 14-21 (2005).

13) Antelo J., Avena M., Fiol S., López R., Arce F., J. Colloid Interface Sci., 285, 476-486 (2005).

14) Ogata F., Kawasaki N., Nakamura T., Tanada S., J. Colloid Interface Sci., 300, 88-93 (2006).

15) Ogata F., Tominaga H., Yabutani H., Kawasaki N., J. Oleo Sci., 60, 133-138 (2011).

16) Boehm H. P., Angew. Chemie., 78, 617-628 (1966).

17) Zeng L., Li X., Liu J., Water Res., 38, 1318-1326 (2004).

18) Ozacar M., J. Hazard. Mater. B, 137, 218-225 (2006).

19) Barrow N. J., J. Soil Res., 37, 787-829 (1999).

20) Huang W., Wang S., Zhu Z., Li L., Yao X., Rudolph V., Haghseresht F., J. Hazard. Mater. B, 158, 35-42 (2008).

21) Sverjensky D. A., Geochim. Cosmochim. Acta, 69, 225-257 (2005).

22) Watanabe Y., Kasama T., Fukushi K., Ikoma T., Komatsu Y., Tanaka J., Moriyama Y., Yamada H., Sep. Sci. Technol., 46, 818824 (2011). 